\title{
Amanita phalloides poisoning and treatment with silibinin in the Australian Capital Territory and New South Wales
}

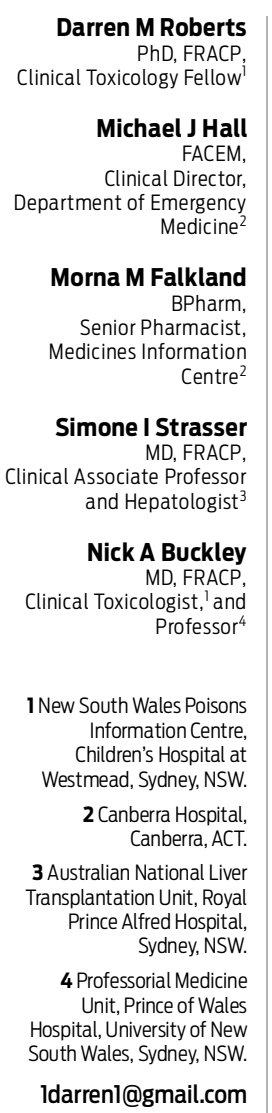

MJA 2013; 198: 43-47 doi: 10.5694/mjal2.11180 manita phalloides ("deathcap" or "whitecap") is a cyclopeptide variety of mushroom that is responsible for more than $90 \%$ of mushroom-related fatalities; one mushroom cap can cause fulminant hepatic failure and death in an adult. ${ }^{1}$ Most reported A. phalloides poisonings occur in Europe. In Australia, most occur in Canberra as A. phalloides grows in the Australian Capital Territory, particularly in the older suburbs of Canberra (which has been attributed to imported oak trees). Cases have also been reported in Victoria. Public health campaigns are commonplace in the ACT in summer and autumn ("mushroom season").

Amatoxin is the most potent hepatotoxin in cyclopeptide mushrooms; it irreversibly binds to RNA polymerase II, causing hepatic necrosis. ${ }^{1}$ The clinical features of $A$. phalloides poisoning are well described (Box 1). The most recent report of $A$. phalloides poisonings in Australia was from the ACT over 10 years ago, describing seven poisonings that occurred between 1988 and $1998 .^{5}$ Since then, a chemically modified derivative of silibinin (silibinin-C2',3-dihydrogen succinate, disodium salt [Legalon SIL, Madaus], referred to hereafter as silibinin) — a purported antidote to $A$. phalloides poisoning that is derived from the milk thistle Silybum marianum - has been stocked by hospitals in the ACT. In 2005, Canberra Hospital imported silibinin for use as an antidote through the Special Access Scheme of the Therapeutic Goods Administration because it is not registered for use in Australia. Sufficient stock was purchased to treat one patient for at least 96 hours at a dosage of $20 \mathrm{mg} / \mathrm{kg} / 24 \mathrm{~h}$, given in 6-hourly doses. This decision was made (despite a lack of good-quality evidence of efficacy) because there was no approved treatment in Australia, there was a plausible mechanism of

\begin{abstract}
Objectives: To report the frequency and clinical outcomes of Amanita phalloides poisoning in the Australian Capital Territory and New South Wales, and the treatments used (including silibinin).
\end{abstract}

Design, setting and patients: Retrospective case series of patients admitted to public hospitals in Canberra and Sydney for suspected $A$. phalloides poisoning between 1999 and 2012 (identified from hospital records and calls to the New South Wales Poisons Information Centre).

Main outcome measures: Frequency of poisoning and the clinical outcomes.

Results: Twelve patients presented with a history suggesting $A$. phalloides poisoning, 10 with probable poisoning and two with possible poisoning. Eight of those with probable poisoning developed significant hepatotoxicity and four died. Silibinin was administered to nine of those with probable poisoning (the other presented before 2005). Maintaining silibinin supply became a challenge during two clusters of poisoning. Eight of the patients with probable poisoning were not long-term residents of the ACT, and six were immigrants from Asia.

Conclusions: The mortality rate due to $A$. phalloides poisoning in this case series was high despite treatment according to current standards, including use of silibinin, and the frequency of hepatotoxicity was more than double that for the previous decade. Ongoing public health campaigns are required. action and some supporting evidence from animal studies, and silibinin is regarded as the standard of care in Europe. In 2010, the silibinin stock level at Canberra Hospital was increased so that there was sufficient stock to treat two patients and, in Sydney, Royal Prince Alfred Hospital also stocked it.

Here, we review cases of A. phalloides poisoning that occurred in the ACT and New South Wales between 1999 and 2012, including patients treated with silibinin.

\section{Methods}

We reviewed the clinical records of patients with possible A. phalloides poisoning who were treated at public hospitals in Canberra and the Australian National Liver Transplantation Unit at Royal Prince Alfred Hospital between January 1999 and May 2012. Patients were identified from clinical databases in departments of emergency medicine and clinical toxicology in the ACT and from call records of the New South Wales Poisons Information Centre. A diagnosis of A. phalloides poisoning was suspected on the basis of a history of mushroom ingestion and subsequent delayed onset of gastroenteritis and hepatitis; blood tests confirming the presence of amatoxin are not available in Australia.

\section{Clinical features of acute Amanita phalloides poisoning ${ }^{1-4}$}

0 to 6-18 hours after ingestion: Asymptomatic

6-24 hours after ingestion: Gastroenteritis, including abdominal pain, nausea, vomiting, diffuse diarrhoea, dehydration with or without hypotension, metabolic acidosis and electrolyte disturbance; normal or mildly deranged renal function and levels of hepatic enzymes

1-7 days after ingestion: Resolving gastrointestinal symptoms, but progressive hepatic failure, coagulopathy, kidney injury (including hepatorenal syndrome); possible progression to multisystem organ failure and a 10\%-30\% mortality rate

$>7$ days after ingestion: Complete resolution of symptoms occurs in most survivors over weeks or months; chronic hepatitis may persist 


\begin{tabular}{|c|c|c|c|c|c|c|}
\hline Patient & $\begin{array}{l}\text { No. of } \\
\text { mushrooms } \\
\text { ingested }\end{array}$ & $\begin{array}{l}\text { Onset of } \\
\text { symptoms }\end{array}$ & $\begin{array}{l}\text { Peak abnormal results } \\
\text { of renal and liver } \\
\text { function tests }\end{array}$ & Treatment & $\begin{array}{l}\text { Predicted } \\
\text { to } \text { die }^{\dagger}\end{array}$ & Outcome \\
\hline A & 1 & $8.5 \mathrm{~h}$ & $\begin{array}{l}\mathrm{Cr}, 137 \mu \mathrm{mol} / \mathrm{L} ; \mathrm{ALT}, \\
7814 \mathrm{U} / \mathrm{L} ; \mathrm{INR}, 3.4 ; \mathrm{La} \\
\text { 4.6 mmol/L }\end{array}$ & $\begin{array}{l}\text { IV fluids, analgesia, antiemetics, MDAC, NAC, } \\
\text { penicillin, silibinin ( } 36 \mathrm{~h} \text { after ingestion) then } \\
\text { silymarin, ICU admission, care by liver } \\
\text { transplantation unit }\end{array}$ & No & Survived, no sequelae \\
\hline B & 10 & $9 \mathrm{~h}$ & $\begin{array}{l}\mathrm{Cr}, 192 \mu \mathrm{mol} / \mathrm{L} ; \mathrm{ALT} \\
3914 \text { U/L; INR, 2.2; La, } \\
16 \mathrm{mmol} / \mathrm{L}\end{array}$ & $\begin{array}{c}\text { IV fluids, penicillin, silibinin ( } 23 \mathrm{~h} \text { after ingestion) } \\
\text { then silymarin, ICU admission, care by liver } \\
\text { transplantation unit }\end{array}$ & No & $\begin{array}{l}\text { Died } 6 \text { days after ingestion } \\
\text { (shock, acute abdomen and } \\
\text { cerebral oedema; hepatic failure } \\
\text { was resolving) }\end{array}$ \\
\hline C & 1 & $8.5 \mathrm{~h}$ & $\begin{array}{l}\mathrm{Cr}, 98 \mu \mathrm{mol} / \mathrm{L} ; \mathrm{ALT}, \\
\text { 4913 U/L; INR, 1.7; La, } \\
\text { 1.6 mmol/L }\end{array}$ & $\begin{array}{l}\text { IV fluids, antiemetics, analgesia, MDAC, NAC, } \\
\text { penicillin, silibinin ( } 46 \mathrm{~h} \text { after ingestion) }\end{array}$ & No & Survived, no sequelae \\
\hline $\mathrm{D}$ & 2 & $11 \mathrm{~h}$ & $\begin{array}{l}\mathrm{Cr}, 88 \mu \mathrm{mol} / \mathrm{L} ; \mathrm{ALT} \\
3701 \mathrm{U} \text {; } \mathrm{INR}, 1.7 ; \mathrm{La} \\
2.3 \mathrm{mmol} / \mathrm{L}\end{array}$ & $\begin{array}{l}\text { IV fluids, penicillin, silibinin ( } 21 \mathrm{~h} \text { after ingestion), } \\
\text { cimetidine, antibiotics and antifungal, care by liver } \\
\text { transplantation unit }\end{array}$ & No & Survived \\
\hline E & $\begin{array}{l}\text { Unclear, } \\
\text { various } \\
\text { mushrooms } \\
\text { ingested in } \\
\text { two meals }\end{array}$ & $\begin{array}{l}25 \mathrm{~h} \text { after first } \\
\text { meal; } 9 \mathrm{~h} \text { after } \\
\text { second meal }\end{array}$ & $\begin{array}{c}\mathrm{Cr}, 73 \mu \mathrm{mol} / \mathrm{L} ; \mathrm{ALT}, \\
7067 \mathrm{U} / \mathrm{L} ; \mathrm{INR}, 2.6 ; \mathrm{La} \\
4.4 \mathrm{mmol} / \mathrm{L}\end{array}$ & $\begin{array}{l}\text { IV fluids, MDAC, acetylcysteine, silibinin ( } 31 \mathrm{~h} \text { after } \\
\text { second meal), ICU admission, care by liver } \\
\text { transplantation unit }\end{array}$ & No & $\begin{array}{l}\text { Survived, persistent but } \\
\text { asymptomatic hepatitis at last } \\
\text { review ( } 5 \text { days after ingestion) }\end{array}$ \\
\hline $\mathrm{F}$ & $\begin{array}{l}\text { Unclear; } \\
\text { perhaps 8-10 }\end{array}$ & $10 \mathrm{~h}$ & $\begin{array}{c}\mathrm{Cr}, 179 \mu \mathrm{mol} / \mathrm{L} ; \mathrm{ALT} \\
7253 \mathrm{U} / \mathrm{L} ; \mathrm{INR}, 8.4 ; \mathrm{La} \\
18 \mathrm{mmol} / \mathrm{L}\end{array}$ & $\begin{array}{l}\text { IV fluids, NAC, MDAC, silibinin ( } 19 \mathrm{~h} \text { after } \\
\text { ingestion), ICU admission, care by liver } \\
\text { transplantation unit, plasma products }\end{array}$ & $\begin{array}{l}\text { No (died } \\
\text { early) }\end{array}$ & $\begin{array}{l}\text { Died } 2.5 \text { days after ingestion, } \\
\text { fulminant hepatic failure and } \\
\text { lactic acidosis }\end{array}$ \\
\hline G & Unclear & $\begin{array}{l}\text { Unknown; had } \\
\text { symptoms for } \\
48 \mathrm{~h} \text { before } \\
\text { presentation }\end{array}$ & $\begin{array}{l}\mathrm{Cr}, 232 \mu \mathrm{mol} / \mathrm{L} ; \mathrm{ALT} \\
3793 \mathrm{U} / \mathrm{L} ; \mathrm{INR}, 12.6 ; \mathrm{La} \\
13.4 \mathrm{mmol} / \mathrm{L}\end{array}$ & $\begin{array}{l}\text { IV fluids, then heparin and interhospital transfer for } \\
\text { investigation and treatment of an ischaemic foot } \\
\text { that resolved without other intervention }{ }^{\ddagger}\end{array}$ & Yes & $\begin{array}{l}\text { Died } 4 \text { days after suspected time } \\
\text { of ingestion, fulminant hepatic } \\
\text { failure and lactic acidosis }\end{array}$ \\
\hline $\mathrm{H}$ & $\begin{array}{l}\text { Unclear; } \\
\text { perhaps 8-10 }\end{array}$ & $10 \mathrm{~h}$ & $\begin{array}{l}\mathrm{Cr}, 119 \mu \mathrm{mol} / \mathrm{L} ; \mathrm{ALT}, \\
7511 \mathrm{U} / \mathrm{L} ; \mathrm{INR},>12 ; \mathrm{La} \\
22 \mathrm{mmol} / \mathrm{L}\end{array}$ & $\begin{array}{l}\text { IV fluids, NAC, MDAC, silibinin ( } 19 \mathrm{~h} \text { after } \\
\text { ingestion), ICU admission, care by liver } \\
\text { transplantation unit, plasma products }\end{array}$ & $\begin{array}{l}\text { Yes (based } \\
\text { on terminal } \\
\text { blood test } \\
\text { results) }\end{array}$ & $\begin{array}{l}\text { Died } 3 \text { days after ingestion, } \\
\text { fulminant hepatic failure and } \\
\text { lactic acidosis }\end{array}$ \\
\hline । & Unclear & $14 \mathrm{~h}$ & $\begin{array}{l}\mathrm{Cr}, 77 \mu \mathrm{mol} / \mathrm{L} ; \mathrm{ALT} \\
63 \mathrm{U} / \mathrm{L} ; \mathrm{INR}, 1.0 ; \mathrm{La} \\
1.3 \mathrm{mmol} / \mathrm{L}\end{array}$ & $\begin{array}{l}\text { IV fluids, MDAC, NAC, silibinin ( } 23 \mathrm{~h} \text { after } \\
\text { ingestion), ICU admission }\end{array}$ & No & Survived, no sequelae \\
\hline J & 5 & $10 \mathrm{~h}$ & $\begin{array}{c}\mathrm{Cr}, 111 \mu \mathrm{mol} / \mathrm{L} ; \mathrm{ALT}, \\
52 \mathrm{U} / \mathrm{L} ; \mathrm{INR}, 1.1 ; \mathrm{La}, \\
1.5 \mathrm{mmol} / \mathrm{L}\end{array}$ & $\begin{array}{l}\text { IV fluids, MDAC, NAC, silibinin (33 h after } \\
\text { ingestion), ICU admission }\end{array}$ & No & Survived \\
\hline K & $\begin{array}{l}\text { Part of a } \\
\text { mushroom }\end{array}$ & $12 \mathrm{~h}$ & $\begin{array}{l}\text { Urea and ALT levels } \\
\text { mildly elevated }\end{array}$ & Observed for $4 \mathrm{~h}$, no follow-up & No & Survived \\
\hline L & 1 & $6 \mathrm{~h}$ (very mild) & No changes & Observed overnight, no progression of symptoms & No & Survived \\
\hline
\end{tabular}

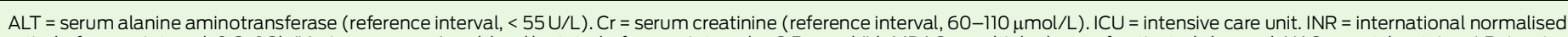

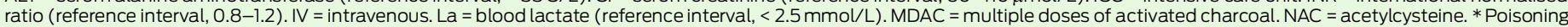

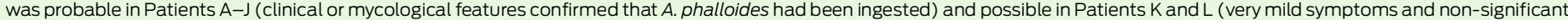
biochemical changes). † Based on prognostication tools. ‡ Patient G presented before 2005, so did not receive silibinin.

De-identified demographic, clinical and treatment data were extracted and two prognostic tools for predicting death (or liver transplant) due to acute $A$. phalloides poisoning were considered.

- Onset of diarrhoea $<8$ hours after mushroom ingestion or INR $\geqslant 6$ on Day 4. These criteria are supported by a study of 27 patients (sensitivity 1.0 and specificity 0.68 for diarrhoea; sensitivity 1.0 and specificity 1.0 for INR) ${ }^{2}$ and a study of 10 patients (sensitivity 1.0 and specificity 1.0 for diarrhoea; sensitivity 0.71 and specificity 1.0 for INR), ${ }^{6}$ but they have been criticised because the supporting studies classified liver transplant recipients as deaths in their analysis. - INR $\geqslant 2.5$ and serum creatinine level $>106 \mu \mathrm{mol} / \mathrm{L}$ from Day 3. The reported predictive utility of these criteria is variable (sensitivity 1.0 and specificity 0.98 in a study of 198 patients; ${ }^{8}$ sensitivity 0.75 and specificity 0.90 in a study of 27 patients; $^{2}$ sensitivity 0.57 and specificity 1.0 in a study of 10 patients $^{6}$ ).

\section{Ethics approval}

This study was approved by the Human Research Ethics Committees of ACT Health, Calvary Health Care ACT, Royal Prince Alfred Hospital and the Children's Hospital at Westmead.

\section{Results}

Over the 12-year study period, 12 patients presented with a history suggesting $A$. phalloides poisoning; they all developed clinical features of poisoning and were admitted to hos- pital (Box 2). The median age of the patients was 36 years (interquartile range, 27-51 years; range, 2-88 years) and eight patients were male. Eight of those with probable poisoning (based on clinical and mycological features) were not long-term residents of the ACT and seven were immigrants (six from Asia, one from Europe).

All the patients had ingested wild mushrooms. One had presented to a Sydney hospital after picking mushrooms in Canberra, transporting them home and then incorporating them into a meal. Two had consumed mushrooms for recreational purposes after they had been misidentified as a hallucinogenic variety. Another had consumed mushrooms believed to be A. phalloides (based on information in 
public health campaigns) for selfpoisoning.

Two patients had very mild symptoms and non-significant biochemical changes, so A. phalloides poisoning was considered possible. The other 10 had probable A. phalloides poisoning owing to marked symptoms and the characteristics of the ingested mushroom; eight developed significant hepatotoxicity (alanine aminotransferase [ALT] level more than 10 times the upper limit of the reference interval) and seven were admitted to an intensive care unit. One patient presented to hospital after 48 hours of gastroenteritis but the history of mushroom ingestion was not noted until about 4 hours before she died. Six patients were transferred from the ACT to the Australian National Liver Transplantation Unit in Sydney. Four of the patients with probable $A$. phalloides poisoning died.

Temporal changes in INR, serum ALT levels and blood lactate levels are shown in Box 3. In most patients, marked changes in INR and ALT levels did not occur until at least 24 hours after mushroom ingestion. In two of the patients who died rapidly, the rate of increase of INR was more marked compared with that in survivors, but the same was not observed with ALT levels. The rate of increase in blood lactate levels was also more marked in patients who died compared with those who survived. The onset of increased INR and ALT levels appears to have been delayed for one of the patients who died and had not received silibinin (Patient G); however, the time of mushroom ingestion by this patient was imprecisely documented.

Multiple therapies were administered, including silibinin to all but one patient with probable A. phalloides poisoning. Silibinin supply was exhausted during the treatment of one patient, who was subsequently given oral silymarin (Legalon [140 mg silymarin capsules], Madaus; a standardised extract of milk thistle seeds that contains silibinin). Other purported antidotes that were administered included intravenous acetylcysteine (given according to dosing guidelines for paracetamol poisoning) and intra- venous penicillin (given in high doses [0.25-1.0 million units $/ \mathrm{kg} /$ day]). Patients also received multiple doses of activated charcoal (50 grams 6-hourly by enteral administration).

Maintaining a supply of silibinin to treat patients was a challenge due to the clustering of events. Of the 10 probable poisonings, nine occurred over the last 4 years of the study period. In six of these cases, the patients presented on a public holiday (New Year's Day) - two on one occasion and four on another. Additional stock was urgently required for the cluster of four patients, which required close communication with pharmacy, clinical toxicology and liver transplant centre colleagues in other states, and with the importing company (which promptly mobilised sufficient stock). However, one of only three hospitals that stocked silibinin during the study period is in South Australia, but this was not known by anyone within the Poisons Information Centre network when treatment for the cluster of four patients was urgently being sought.

From our experience, elevated INR and blood lactate levels appeared to be the best prognostic markers. Other prognostic tools (listed in the Methods) did not provide useful advance warning of death - they met criteria only within several hours of death in the four patients who died. One death is notable because the INR values and ALT levels suggested resolution of hepatic injury, but the patient had progressive severe metabolic acidosis and hypoalbuminaemia and, 6 days after mushroom ingestion, developed an acute abdomen and subsequently died of cerebral oedema. The three patients who died rapidly with hepatic failure also had very severe lactic acidosis (Box 3). Severe gastrointestinal tract toxicity may be a significant contributory cause of death and may complicate liver transplantation. ${ }^{9}$ Toxicity progressed rapidly in two patients who were thought to have ingested the largest doses (about 810 mushrooms). Because of the small number of patients, it was not possible to explore the effectiveness of treatments.
3 Temporal changes in INR, serum ALT levels and blood lactate levels in patients with probable Amanita phalloides poisoning
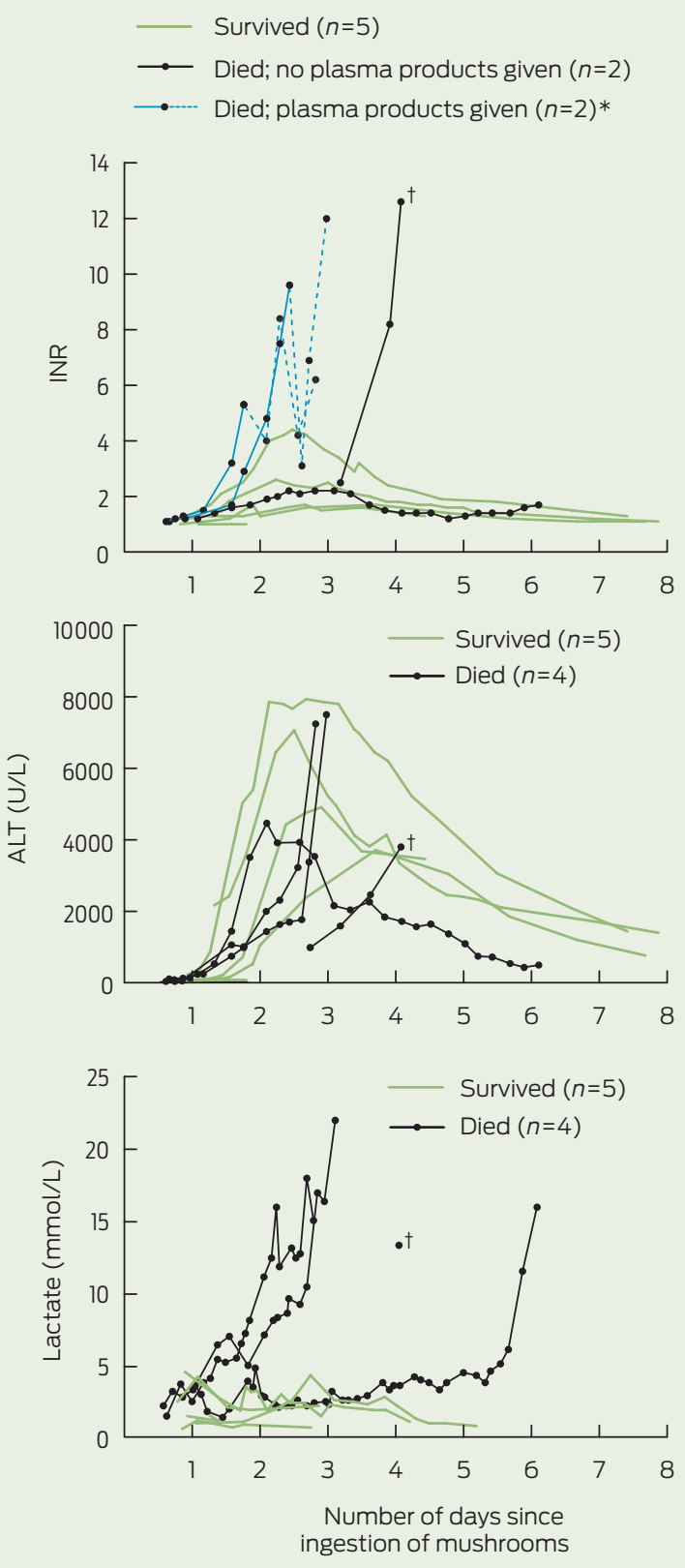

ALT = alanine aminotransferase. INR = international normalised ratio. * Change from solid blue line to dashed blue line indicates start of treatment with plasma products. $\dagger$ Time of ingestion unclear, so times are estimates.

\section{Discussion}

This case series shows that $A$. phalloides poisoning is an ongoing public health concern. It is also the first report of silibinin use in Australia for A. phalloides poisoning. Despite availability of silibinin, multiple ingestions from 2000 to 2012 led to severe poisoning, including four 
deaths. Compared with data from the previous decade, ${ }^{5}$ the number of patients with hepatotoxicity more than doubled and the number of deaths quadrupled. However, the events were clustered and sporadic. People who do not reside in the ACT appear to be at higher risk, as do immigrants (six victims had recently arrived from Asia, where consumption of wild mushrooms is commonplace, and had limited English language skills). Those who consume mushrooms for recreational purposes may also be vulnerable.

Ongoing review of public health campaigns and existing treatment protocols is occurring and appears to be warranted. However, increased awareness of the toxicity of A. phalloides may have the counter-effect of prompting its use for self-harm, which is concerning given the low efficacy of existing treatments.

The approach to treating patients with suspected A. phalloides poisoning includes prompt consideration of the diagnosis and identification of the mushroom if a fresh specimen or a sample of gastric contents is available. This requires liaison with a mycologist and performance of the Meixner test. The Meixner test is conducted by adding hydrochloric acid to a sample of mushroom placed on newspaper; a blue colour change suggests the presence of amatoxin, although false positive results have been reported. ${ }^{1}$ Treatment includes supportive care and gastrointestinal decontamination, and antidote use should be considered. ${ }^{10}$ Fluid resuscitation is required during the gastroenteritis phase to restore haemodynamic stability and maintain renal perfusion. Amatoxin is subject to enterohepatic recirculation, so multiple doses of activated charcoal should be given to limit reabsorption. Nasobiliary drainage has also been employed to reduce enterohepatic recirculation. ${ }^{11}$ Extracorporeal treatments have been trialled, but efficacy is inadequately quantified.

Electrolyte abnormalities should be corrected, and liver enzyme levels, INR, and lactate levels should be monitored for prognosticative purposes. Indications for liver transplantation are debated. Where possible, transplantation should be delayed until at least 2-4 days after poisoning to allow elimination of amatoxin to prevent graft poisoning. ${ }^{12}$ Early predictors of severe poisoning (but not necessarily death) may also help decision making regarding transfer to specialised liver units.

Multiple antidotes are currently used to treat patients with A. phalloides poisoning. ${ }^{1,10}$ The evidence of efficacy is limited for all treatments, largely due to the difficulties associated with human studies of an infrequent and sporadic type of poisoning. Two analyses of observational studies in human poisonings have supported the role of silibinin and acetylcysteine, ${ }^{10,13}$ however, positive findings are limited by potential publication bias. ${ }^{10,13}$ None of the treatments have been subjected to dose-response or controlled trials in humans. Many animal studies are of limited clinical relevance because treatments are not delayed. Further, in-vitro studies have demonstrated effects of benzylpenicillin, acetylcysteine and silibinin in human cultured hepatocytes, ${ }^{14-16}$ but not canine hepatocytes. ${ }^{17}$ A study in pigs demonstrated no beneficial effects of silibinin, acetylcysteine, benzylpenicillin, cimetidine or thioctic acid administered 4 hours after poisoning. ${ }^{18}$ In our case series, four out of 10 patients with clinically significant poisoning died, despite the use of intravenous silibinin and other treatments in nine of them. The optimal doses and timing of antidotes, and the range of amatoxin ingestion for which antidotes are effective, are unknown.

Despite these limitations, silibinin continues to be imported into Australia and is widely used elsewhere. Decisions regarding stock holdings of silibinin require consideration of cost (about \$1400/day/patient), stock expiration, and time to obtain replacement or additional stock (potentially long, as it is not marketed in Australia). Our experience suggests that Poisons Information Centre knowledge of silibinin stocks, and rapid communication with the distributor and hospitals is required. A coordinated national approach (eg, a national inventory of antidotes) may be useful given that $A$. phalloides poisoning is not limited to the ACT.
A blood test that detects amatoxin would be useful to confirm exposures for epidemiological purposes. If rapidly available, a quantitative assay might assist existing prognostic tests, although more research is first required to guide interpretation of these results - for example, to develop a nomogram for risk stratification, similar to the approach used for paracetamol poisoning. An amatoxin assay may also be useful for determining when the blood concentration of amatoxin is sufficiently low in an individual patient to allow liver transplantation to proceed, when required, without subsequent poisoning of the graft.

Management is controversial in patients who present early after ingestion of mushrooms that may be A. phalloides but do not have clinical features of significant poisoning. We identified two such patients with favourable outcomes (although $A$. phalloides ingestion was not confirmed). In such cases, the risk of $A$. phalloides ingestion should be clarified by consulting a mycologist and/ or conducting a Meixner test. Early intervention, including decontamination and antidotes, should be considered after consulting a Poisons Information Centre.

Clinical trials on antidotes for $A$. phalloides poisoning would be extremely helpful as there are no treatments with good evidence, and there may be as yet unknown but cheaper and more widely available alternatives to silibinin. An observational study of silibinin (ClinicalTrials.gov Identifier, NCT00915681) is underway, but no randomised controlled trials are currently registered and most guidelines follow the accepted standard practice in Europe.

A. phalloides poisoning is a public health problem in Australia, particularly the ACT, and the mortality rate is potentially high. Based on currently available data, we recommend treatment with supportive care, multiple doses of activated charcoal, intravenous silibinin, and acetylcysteine, as well as consideration of liver transplantation.

Acknowledgements: We thank Emily Diprose for helpful comments on this article.

Competing interests: No relevant disclosures.

Received 26 Jul 2012, accepted 3 Dec 2012. 
1 Berger KJ, Guss DA. Mycotoxins revisited: part I. J Emerg Med 2005; 28: 53-62.

2 Escudié L, Francoz C, Vinel JP, et al. Amanita phalloides poisoning: reassessment of prognostic factors and indications for emergency liver transplantation. J Hepatol 2007; 46: 466-473.

3 Giannini L, Vannacci A, Missanelli A, et al. Amatoxin poisoning: a 15-year retrospective analysis and follow-up evaluation of 105 patients. Clin Toxicol (Phila) 2007; 45: 539-542.

4 Krenová M, Pelclová D. Potential hepatotoxic and nephrotoxic substances reported to the Czech Toxicological Information Centre in the past 3 years. J Toxicol Clin Toxicol 2004; 42: 498.

5 Trim GM, Lepp H. Hall MJ, et al. Poisoning by Amanita phalloides ("deathcap") mushrooms in the Australian Capital Territory. Med J Aust 1999: 171: 247-249.

6 Ferreira R, Romãozinho JM, Amaro P, et al. Assessment of emergency liver transplantation criteria in acute liver failure due to $A$ manita phalloides. Eur I Gastroenterol Hepatol 2011; 23: 1226-1232.

7 Ganzert M, Felgenhauer N, Zilker T. Reassessment of predictors of fatal outcome in amatoxin poisoning: some critical comments. J Hepatol 2007; 47: 424-425.

8 Ganzert M, Felgenhauer N, Zilker T. Indication of liver transplantation following amatoxin intoxication. J Hepatol 2005; 42: 202-209.

9 Pinson CW, Daya MR, Benner KG, et al. Liver transplantation for severe Amanita phalloides mushroom poisoning. Am J Surg 1990; 159: 493-499.

10 Enjalbert F, Rapior S, Nouguier-Soulé J, et al. Treatment of amatoxin poisoning: 20-year retrospective analysis. J Toxicol Clin Toxicol 2002; 40: 715-757.

11 Madhok M, Scalzo AJ, Blume CM, et al. Amanita bisporigera ingestion: mistaken identity, doserelated toxicity, and improvement despite severe hepatotoxicity. Pediatr Emerg Care 2006; 22: $177-180$.

12 Jaeger A, Jehl F, Flesch F, et al. Kinetics of amatoxins in human poisoning: therapeutic implications.J Toxicol Clin Toxicol 1993; 31: 63-80.

13 Poucheret P. Fons F, Doré JC, et al. Amatoxin poisoning treatment decision-making: pharmaco-therapeutic clinical strategy assessment using multidimensional multivariate statistic analysis. Toxicon 2010; 55 1338-1345.

14 Magdalan J, Piotrowska A, Gomulkiewicz A, et al. Benzylpenicyllin and acetylcysteine protection from $\alpha$-amanitin-induced apoptosis in human hepatocyte cultures. Exp Toxicol Pathol 2011; 63: 311-315.

15 Magdalan J, Ostrowska A, Piotrowska A, et al. Benzylpenicillin, acetylcysteine and silibinin as antidotes in human hepatocytes intoxicated with alpha-amanitin. Exp Toxicol Pathol 2010; 62: 367-373.

16 Magdalan J, Piotrowska A, Gomulkiewicz A, et al. Influence of commonly used clinical antidotes on antioxidant systems in human hepatocyte culture intoxicated with alphaamanitin. Hum Exp Toxicol 2011; 30: 38-43.

17 Magdalan J, Ostrowska A, Piotrowska A, et al. Failure of benzylpenicillin, $\mathrm{N}$-acetylcysteine and silibinin to reduce alpha-amanitin hepatotoxicity. In Vivo 2009; 23: 393-399.

18 Tong TC, Hernandez M, Richardson WH 3rd, et al. Comparative treatment of alpha-amanitin poisoning with $\mathrm{N}$-acetylcysteine, benzylpenicillin, cimetidine, thioctic acid, and silybin in a murine model. Ann Emerg Med 2007; 50: $282-288$.

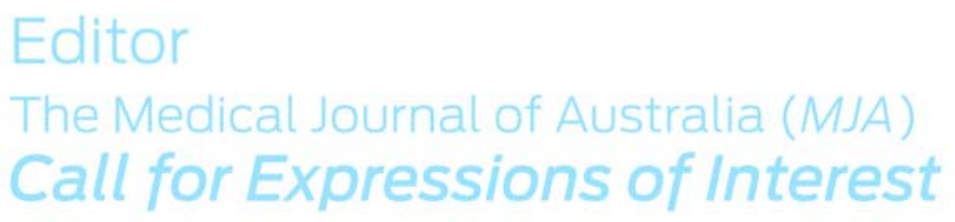

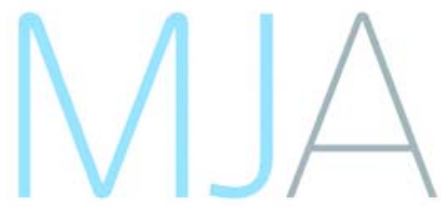

The Medical Journal of Australia

The Medical Journal of Australia is Australia's premier general medical journal. It is the journal of the Australian Medical Association, which confers editorial independence, and is published by the Australasian Medical Publishing Company (AMPCo).

The AMPCo Board is seeking to appoint an outstanding individual to the position of Editor of the Medical Journal of Australia on a full-time basis.

The Journal's offices are in the Sydney CBD.

Formal Qualifications:

- Formal medical qualifications essential - Postgraduate medical qualifications desirable Demonstrated Experience/Abilities:

- Experience in scientific investigation and research

* Experience in clinical medical practice

- Knowledge of the issues confronting the medical and health care community in Australia

- Highly developed English language and communication skills

-Substantial understanding of the requirements of academic publishing

- Strong leadership ability and experience managing a team of staff

- Proven time management, project management and people management skills

- Prior experience in medical publishing and editing highly desirable

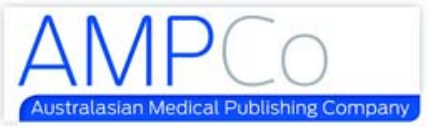

Please direct your expression of interest (by 9 February 2013) to: Chairman, AMPCo Board Tel: (02) 95626602 - mshepherd@ampco.com.au 
Research 
Research 